\title{
Hooked on crystallography
}

\author{
Michael Ruf and Bruce C. Noll
}

Bruker AXS Inc., 5465 East Cheryl Parkway, Madison, WI, 53711 USA (michael.ruf@bruker.com)

We all remember the thrill when our first molecule structure popped up on a computer screen, when suddenly the 2D textbook world of chemistry turned 3D and you could rotate a molecule and look at it from different perspectives. Molecules started to make sense.

Crystallographic software and hardware have become so powerful that we can now go from growing crystals to creating animated gifs of molecules for sharing on social media in less than a class period. This presentation will give examples for taking students on a thrill ride that will get them hooked on crystallography. 